\title{
A originalidade das línguas indígenas brasileiras
}

\author{
por Aryon Dall'Igna Rodrigues
}

Conferência proferida por ocasião da inauguração do Laboratório de Línguas Indígenas do Instituto de Letras da Universidade de Brasília, em 8 de julho de 1999.

\section{Quantidade e diversidade}

Embora a maioria dos brasileiros tenha a impressão de viver num país monolíngue, o Brasil é na verdade multilíngue: nele são aprendidas como línguas maternas cerca de 200 línguas. A singularidade linguística do Brasil está em que uma dessas línguas, o Português, é hoje extremamente majoritária e as demais são todas extremamente minoritárias. As pessoas que têm línguas maternas minoritárias no Brasil constituem apenas $0,5 \%$ da população total do país, cerca de 750.000 indivíduos. Deste contingente a maior parte, $60 \%$, fala a que é a segunda língua do Brasil em termos demográficos - o Japonês. Os $40 \%$ restantes, cerca de 300.000 pessoas, distribuem-se pelas outras línguas de minorias asiáticas (Chinês, Coreano, Árabe, Armênio, etc.) e europeias (Alemão, Italiano, Polonês, Grego moderno, Húngaro, Ucraniano, Ídiche, Lituano, etc.) e pelas línguas indígenas. Embora existam hoje no Brasil cerca de 220 povos indígenas, o número de línguas indígenas ainda faladas é um pouco menor, cerca de 180 , pois mais de vinte desses povos agora falam só o Português, alguns passaram a falar a língua de um povo indígena vizinho e dois, no Amapá, falam o Crioulo Francês da Guiana. A população total dos povos indígenas é agora de cerca de 190.000 pessoas, mas destas só cerca de 160.000 falam as 180 línguas indígenas. Isto implica numa média de menos de 900 falantes por língua. Como, naturalmente, a distribuição é desigual, algumas dessas línguas são faladas por cerca de 20.000 pessoas ao passo que outras o são por menos de 20. Há grande diversidade entre as línguas indígenas do Brasil, tanto de natureza tipológica, quanto de natureza genética. Do ponto de vista tipológico há tanto línguas de gramática predominantemente analítica, quanto outras fortemente polissintéticas, com características que só se encontram nas Américas; tanto línguas com inventários fonológicos abundantes, como outras com um número extremamente reduzido de vogais e consoantes, assim como há línguas tonais, que caracterizam as palavras por sílabas de tom mais alto e de tom mais baixo, e línguas que, como a maioria das europeias, só usam o tom para caracterizar tipos de sentenças. Do ponto de vista genético, que permite classificar as línguas em conjuntos com origem comum mais próxima 
ou mais remota, as 180 línguas indígenas brasileiras se distribuem por pouco mais de 40 conjuntos, a que se costuma dar o nome de famílias linguísticas. Dez destes constam hoje de uma só língua, a qual, por ser a única e não apresentar parentesco com as demais conhecidas, é também chamada de língua isolada. O número de línguas nas outras famílias varia de duas a trinta. Este último é o número de línguas da família Tupí-Guaraní no Brasil, que é a mais distribuída sobre nosso território, com línguas no Amapá e norte do Pará e com outras no Paraná, Santa Catarina e Rio Grande do Sul, com umas no litoral atlântico e outras em Rondônia, assim como nos principais afluentes meridionais do rio Amazonas, no Madeira, no Tapajós, no Xingu e também no Tocantins e Araguaia. Outras grandes famílias são a Jê, que tem línguas distribuídas desde o Maranhão até o Rio Grande do Sul, a Aruak no oeste e no leste da Amazônia, em Mato Grosso e em Mato Grosso do Sul, e a Karíb ao norte do rio Amazonas, nos estados do Amazonas, Roraima, Pará e Amapá, mas com algumas línguas ao sul daquele rio, ao longo de seu afluente Xingu, nos estados do Pará e Mato Grosso. Dez famílias, inclusive a Tupí-Guaraní, são reconhecidas como aparentadas geneticamente num nível mais remoto, constituindo um conjunto de conjuntos, a que se chama tronco linguístico, nesse caso o tronco Tupí. Há evidências de que a família Karíb também está aparentada geneticamente com o tronco Tupí, mas ainda não estão claros maiores detalhes dessa conexão. Outro tronco é o Macro-Jê, que reúne 12 famílias, um a das quais é a família Jê. Há sugestões sobre outras relações genéticas entre diversas famílias, mas são ainda meramente especulativas.

\section{Propriedades fonológicas incomuns ou únicas}

Qualquer língua opera com unidades de forma e significado e com regras de combinação dessas unidades. As formas dessas unidades, que se chamam morfemas, têm sua substância formada por unidades de outra ordem, os fonemas, estes constituídos por sons produzidos pelos órgãos da fala do corpo humano. $\mathrm{O}$ repertório de sons que podem constituir os fonemas é muito grande, mas cada língua utiliza só um conjunto bastante limitado. Como alguns fonemas podem ser constituídos por dois ou mais sons, os inventários de fonemas são ainda mais limitados. As línguas diferem bastante, entretanto, seja em seu número de fonemas, seja na qualidade destes. Em todas elas, entretanto, distinguimos duas classes principais de fonemas, os fonemas glotais, produzidos basicamente na laringe, e os fonemas supraglotais, produzidos basicamente acima da laringe, ou seja, na faringe e na boca. Os fonemas glotais são as vogais, de uso universal, e o oclusivo e o fricativo glotais, que não se usam em todas as línguas. Os supraglotais são as consoantes, também universais enquanto classe de fonemas. As consoantes se subdividem em diversas categorias, segundo o modo como se produzem por articulação dos órgãos supraglotais (língua, palato, lábios) e segundo a localização da articulação. 
Uma das línguas indígenas brasileiras tem o que é provavelmente o menor inventário de fonemas no mundo: a língua Pirahã falada junto a um dos afluentes do rio Madeira, no Amazonas, tem apenas dez fonemas - seis consoantes, três vogais e o fricativo glotal. Esta, que é a única ainda falada da família Múra e que está bem documentada e analisada, é uma língua tonal, com dois fonemas tonais, um tom alto e um tom baixo, que concorrem com as consoantes, as vogais e o fricativo glotal para caracterizar cada sílaba das palavras. Do ponto de vista fonético, o Pirahã é particularmente notável por ter um som D até hoje só encontrado nele e em nenhuma outra língua do mundo, o qual é produzido com o mesmo movimento inicial da língua com que se faz o nosso $r$ de arara, mas aplicando-se as bordas laterais desse órgão aos dentes molares superiores (como na produção do nosso 1), e projetando-se a ponta do mesmo para fora da boca por entre os dentes incisivos e os lábios; e um outro som, não exclusivo, mas raríssimo como som linguístico, B, produzido pela vibração dos lábios acompanhada de vibração das cordas vocais (Everett 1979, 1982, Rodrigues 1984). Som análogo a este último e igualmente incomum nas línguas do mundo, produzido da mesma maneira, mas sem a vibração das cordas vocais, portanto P, encontra-se em palavras da língua Arara da família Karíb, no baixo Xingu (Souza 1988). A língua Suruí ou Paitér de Mato Grosso (família Mondé) tem um som até agora observado só nela, uma consoante fricativa lateral surda interdental L (e não alveolar, como a que tem sido descrita para muitas outras línguas) (van der Meer 1982, Rodrigues 1984). Do ponto de vista fonológico, isto é, da economia dos sons, o Pirahã também é particularmente notável. Seu sistema consonantal é um dos mais anárquicos que se conhecem, muito pouco configuracional. Por exemplo, o som oclusivo velar $[\mathrm{k}]$, que por si só não constitui um fonema, ocorre como variante tanto do fonema oclusivo labial /p/, como do oclusivo dental /t/ e, ainda, da sequência hi. Há, nesse sistema, dois fonemas oclusivos sonoros, um labial /b/ e o outro não labial $/ \mathrm{g} /$. Ambos têm uma variante nasal e outra líquida, mas enquanto para /b/ essas são da mesma qualidade labial, [m] e [B], respectivamente, para /g/, que é basicamente velar, elas não são velares, mas sim dentais, [n] e [L], respectivamente (Everett 1979, 1986, Rodrigues 1984). A língua Maxakalí, da família do mesmo nome, em Minas Gerais, é a única no mundo com variantes vocálicas para todas as suas consoantes. Esta língua explora só minimamente as possibilidades de produzir consoantes: todas as suas consoantes são oclusivas, uma série de quatro surdas (isto é, sem vibração das cordas vocais) e outra de quatro sonoras (com vibração das cordas vocais). Mas as sonoras tornam-se inteira ou parcialmente nasais em determinados contextos e tanto as surdas como as sonoras apresentam, segundo os contextos, variantes pré-vocalizadas ou inteiramente vocalizadas, isto é, como puras vogais fonéticas (Gudschinsky, Popovich \& Popovich 1970, Rodrigues 1981, Wetzels \& Sluyters 1995). Outros fenômenos fonológicos de interesse teórico descobertos em línguas indígenas do Brasil incluem segmentos 
fonológicos complexos, com até três fases sucessivas de realização fonética, tanto consonantais como vocálicos, em línguas como o Kaingáng do Paraná (família Jê) (Rodrigues e Cavalcante 1982, Cavalcante 1987), o Yuhúp (família Makú) da bacia do rio Negro, no Amazonas (del Vigna 1991) e o Maxakalí (família Maxakalí) em Minas Gerais (Gudschinsky, Popovich \& Popovich 1970, Pereira 1991); a produção de sons nasais em contacto com fonemas assilábicos glotais, como em Pirahã (família Múra) e em Mawé (família Mawé, tronco Tupí) (Rodrigues 1984, Sândalo 1991); a nasalização da vogal $a$ por processo fonológico de compactação em Kaingáng e em Tapirapé (Rodrigues 1981); etc.

\section{Propriedades gramaticais incomuns ou únicas}

Enquanto diversas línguas indígenas sul-americanas têm elementos pronominais de primeira pessoa do plural, equivalentes ao nós, nos, nosso do Português, muitas outras distinguem duas expressões pronominais da chamada primeira pessoa do plural, uma inclusiva, que inclui a pessoa com quem se fala ('eu e você' ou 'eu e vocês') e outra exclusiva, que exclui essa pessoa ('eu e ele' ou 'eu e eles'). Essa é uma distinção que ocorre em diferentes partes do mundo. Há entretanto uma distinção que até agora só foi observada numa língua do Brasil, o Tupinambá (fam. Tupí-Guaraní). Nesta há três pronomes «nós», um exclusivo e dois inclusivos. Estes dois últimos se distinguem pela presença ou ausência de uma terceira pessoa que o falante põe em foco em seu discurso: jané significa 'eu e você' ou 'eu e vocês' ou 'eu, você e outros', ao passo que asé quer dizer 'ele e eu e você(s)' ou 'eles e eu e você(s)'. Nos verbos dessa língua há prefixos que marcam os sujeitos em concordância com esses pronomes, $j a-\mathrm{e}$ $o-$, respectivamente; mas esses dois prefixos se usam não só quando o sujeito é «nós», mas também quando é «ele» ou «eles», isto é, apenas de 3a. pessoa, caso em que $o$ - se refere a uma 3a. pessoa que é o foco do discurso, enquanto que $j a$ indica uma terceira pessoa que não é o foco. Em consequência, a forma verbal ojkutúk pode significar 'nós o ferimos' ou 'ele o feriu', e o mesmo se dá com a forma jajkutúk. Essa situação se explica não só pela distinção entre 3a. pessoa focal e não focal, mas também pela importância que se dá ao contraste entre falante e ouvinte: quando os dois agem juntos (situação de «nós inclusivo») não há contraste entre eles, da mesma forma como também não há contraste quando só uma terceira pessoa age («ele(s)»): daí o uso das mesmas marcas de «pessoa»; as demais marcas de pessoa no verbo referem-se a situações em que há esse contraste: $a$ - 'eu (você não)', oro- 'eu e ele ou eles (você não)', ere'você (eu não)', pe- 'você e ele ou eles (eu não)'. Assim, nessa língua, 'eu e você' exprime-se exatamente como 'nem eu nem você'. (Rodrigues 1990, 1993). Embora até os anos 70 se considerasse um princípio universal a construção de orações negativas mediante o acréscimo às afirmativas correspondentes de um ou mais morfemas de negação, portanto por um aumento de substância, uma 
língua de Rondônia, o Karitiána (família Arikém, tronco Tupí) produz orações negativas mediante a supressão das marcas de aspecto e tempo no verbo, portanto por redução de substância (Landin 1984). Outro suposto princípio universal foi desfeito nos anos 70 pelo estudo de outra língua amazônica. Com base no exame de línguas dos outros continentes tipologistas haviam concluído que não existiam línguas em que a ordem básica das orações transitivas tivesse o objeto direto nominal em primeira posição. O Hixkaryána, língua da família Karíb, no rio Nhamundá no Amazonas, desfez essa conclusão (Derbyshire 1977). Entre outros fenômenos gramaticais únicos ou incomuns podemos citar a incorporação de posposições no sintagma verbal em Panará, da família Jê, hoje na bacia do Tapajós (Dourado 1994), e em Nadêb (família Makú) da bacia do rio Negro, no Amazonas (Weir 1990); a incorporação recursiva de nomes no sintagma verbal do mesmo Nadêb (Weir 1990); referência alternada (switch reference) não apenas no sujeito de orações coordenadas ou subordinadas, mas também no objeto direto e nos complementos indiretos, como em algumas línguas da família Tupí-Guaraní (Silva 1999); etc.

\section{O porquê da originalidade}

\subsection{A antiguidade do homem na América do Sul}

O povoamento da América do Sul por seres humanos é recente em relação à antiguidade do homem sobre a Terra: as estimativas mais conservadoras são de cerca de 12.000 anos antes do presente, mas resultados mais recentes de pesquisas arqueológicas apontam para a possibilidade de que o homem já estivesse aqui há uns 50.000 anos. Mesmo com as estimativas mais cautelosas, os grupos humanos que aqui penetraram tiveram um longuíssimo tempo para ir ocupando o novo espaço, adaptando-se a suas características ecológicas, aumentando sua população, dividindo-se sucessivamente em grupos que se distanciaram mais e mais, e mais e mais se diferenciaram, desenvolvendo novos hábitos, novos conhecimentos, novas atitudes. Como uma propriedade universal das línguas é sua contínua mudança através das gerações e sua diversificação quando se reduz ou se perde o contacto entre partes de seus falantes, a língua ou as línguas que os imigrantes pré-históricos trouxeram para a América do Sul tiveram um tempo considerável para modificar-se e diferenciar-se, multiplicando-se em diversas famílias linguísticas. Todos os componentes de uma língua - seu sistema de sons, seu sistema morfológico e sintático e seu vocabulário, assim como suas estratégias de construção do discurso - mudam no curso do tempo, em consequência de reajustes internos desses sistemas e devido a mudanças na cultura e organização social do povo que a fala e a influências de outras línguas com que ela entra em contacto em determinadas circunstâncias. Os resultados dessas mudanças frequentemente coincidem com fenômenos já existentes em 
outras línguas, mas às vezes constituem inovações. Tais inovações podem propagar-se para outras línguas que entrem em contacto com a língua inovadora e podem, assim, tornar-se características de uma determinada área geográfica, mas também podem ficar restritas somente à família genética descendente da língua inovadora. Quando as características de uma região geográfica mantêm relativamente isolados os povos que nela vivem, as inovações não se propagam além dessa região, da mesma forma como inovações ocorridas fora dessa área aí não penetram.

\subsection{O relativo isolamento da América do Sul}

A América do Sul é quase uma ilha, é uma grande península ligada às Américas Central e do Norte apenas pelo estreitíssimo istmo do Panamá e separada dos demais continentes pelos dois maiores oceanos, o Atlântico e o Pacífico. A natureza insular da América do Sul deve ter tido como consequência que inovações linguísticas não coincidentes com fenômenos já existentes fora dela ficaram restritas a línguas daqui, da mesma forma como fenômenos linguísticos surgidos em outras regiões do mundo após o povoamento desta, não puderam propagar-se até aqui. Em vista disso, não pode ser surpreendente, antes é de esperar-se que várias línguas indígenas do Brasil, assim como de outras partes da América do Sul, apresentem fenômenos originais em relação ao que é conhecido dos demais continentes. Que só muito recentemente tenham começado a ser percebidos tais fenômenos deve-se essencialmente a dois fatores: primeiro, a pesquisa científica das línguas indígenas no Brasil e na América do Sul em geral é muito recente e ainda muito pouco desenvolvida e, segundo, ainda são muito poucos os pesquisadores e para estes há muito pouco apoio institucional.

\section{A perda da quantidade e da diversidade}

A lentidão com que se tem desenvolvido a pesquisa científica das línguas indígenas no Brasil revela-se extremamente grave quando se verifica que essas línguas, desde o descobrimento do Brasil pelos europeus, têm estado continuamente submetidas a um processo de extinção (ou mesmo de exterminação) de espécies de consequências extremamente graves. Hoje há cerca de 180 línguas indígenas neste país, mas estas são apenas 15\% das mais de mil línguas que se calcula terem existido aqui em 1500 (Rodrigues 1993a, 1993b). Essa extinção drástica de cerca de 1000 línguas em 500 anos (a uma média de duas línguas por ano) não se deu apenas durante o período colonial, mas manteve-se durante o período imperial e tem-se mantido no período republicano, às vezes, em certos momentos e em certas regiões, com maior intensidade, como durante a recente colonização do noroeste de Mato Grosso e de Rondônia. Quase todas as línguas indígenas que se falavam nas regiões 
Nordeste, Sueste e Sul do Brasil desapareceram, assim como desapareceram quase todas as que se falavam na calha do rio Amazonas. Essa enorme perda quantitativa implica, naturalmente, uma grande perda qualitativa. Línguas com propriedades insuspeitadas desapareceram sem deixar vestígios, e provavelmente algumas famílias linguísticas inteiras deixaram de existir. As tarefas que têm hoje os linguistas brasileiros de documentar, analisar, comparar e tentar reconstruir a história filogenética das línguas sobreviventes é, portanto, uma tarefa de caráter urgente urgentíssimo. Muito conhecimento sobre as línguas e sobre as implicações de sua originalidade para o melhor entendimento da capacidade humana de produzir línguas e de comunicar-se ficará perdido para sempre com cada língua indígena que deixa de ser falada.

\section{A situação atual}

A simples menção do número de 180 línguas indígenas existentes hoje no Brasil pode dar uma falsa ideia da realidade. Uma maior aproximação com esta realidade só pode ser obtida mediante consideração dos dados demográficos referentes a cada língua. Seria demasiado longo apresentar aqui em detalhe esses dados, por isso limito-me a agrupar as línguas dentro de certos limites demográficos, isto é, segundo o número de pessoas que as falam, e a mencionar o número de línguas em cada grupo. Há apenas uma língua com pouco mais de 30.000 falantes, duas entre 20.000 e 30.000 , outras duas entre 10.000 e 20.000 ; três entre 5.000 e $10.000 ; 16$ entre 1.000 e $5.000 ; 19$ entre 500 e 1.000; 89 de 100 a 500 e 50 com menos de 100 falantes. A metade destas últimas, entretanto, tem menos de 20 falantes. Em resumo: das 180 línguas apenas 24, ou 13\%, têm mais de 1000 falantes; 108 línguas, ou 60\%, têm entre 100 e 1000 falantes; enquanto que 50 línguas, ou $27 \%$, têm menos de 100 falantes e metade destas, ou $13 \%$, têm menos de 50 falantes (Rodrigues1993c).

Em qualquer parte do mundo línguas com menos de 1000 falantes, que é a situação de $87 \%$ das línguas indígenas brasileiras, são consideradas línguas fortemente ameaçadas de extinção e necessitadas, portanto, de pesquisa científica urgentíssima, assim como de fortes ações sociais de apoio a seus falantes, que como, comunidades humanas, estão igualmente ameaçados de extinção cultural e, em não poucos casos, de extinção física.

\section{O Laboratório de Línguas Indígenas}

O objetivo maior do Laboratório de Línguas Indígenas do Instituto de Letras da Universidade de Brasília é o estabelecimento de um espaço institucional para promover a documentação, análise, descrição, comparação não só das línguas, mas também das situações em que se encontram estas. O laboratório deve tornarse um centro de troca de conhecimentos e de experiências por pesquisadores de diversas instituições, do País e do exterior, um espaço de trabalho e de 
treinamento para novos pesquisadores e uma agência de informações e consultas sobre o conhecimento linguístico relevante para pesquisadores e agentes sociais e educacionais, que cooperam com comunidades indígenas, assim como diretamente para essas mesmas comunidades.

\section{Referências}

Cavalcante, M. P., 1987. Fonologia e morfologia da língua Kaingáng: o dialeto de São Paulo comparado com o do Paraná. Tese de doutorado, UNICAMP, Campinas. Derbyshire, D. C., 1977. «Word order universals and the existence of OVS languages». Language Inquiry 8:590-599.

Dourado, L. G., 1994. «Incorporação de posposição na língua Panará».

Comunicação apresentada no Congresso Internacional da Associação Brasileira de Lingüística, Salvador. Everett, D., 1979. Aspectos da fonologia do Pirahã. Dissertação de mestrado, UNICAMP, Campinas.

, 1982. «Phonetic rarities in Pirahã». Journal of the International Phonetics Association 12:94-96.

, 1986. «Pirahã». Handbook of Amazonian Languages, vol. 1:200-325 (org. por D. C. Derbyshire e G. K. Pullum), Mouton de Gruyter, Berlim.

Gudschinsky, S. C., H. \& F. Popovich, 1970. «Native reaction and phonetic similarity in Maxakalí». Language 46:77-88.

Landin, D. J., 1984. «An outline of the syntactic structure of Karitiâna sentences». Série Lingüística 11: Estudos sobre línguas Tupi do Brasil (org. por R. A. Dooley) 219-254. Brasília: Summer Institute of Linguistics.

Meer, T. van der, 1982. Fonologia da língua Suruí. Dissertação de mestrado, UNICAMP, Campinas.

Pereira, D. G., 1991. Alguns aspectos gramaticais da língua Maxakalí. Dissertação de mestrado, UFMG.

Rodrigues, A. D., 1984. «Contribuições das línguas brasileiras para a fonética e a fonologia». Language in the Americas (org. por D. F. Solá) 263-267. Ithaca: Cornell University.

, 1993a. «Línguas indígenas: 500 anos de descobertas e perdas». D.E.L.T.A. 9(1):83-103. São Paulo.

, 1993b. «Línguas indígenas: 500 anos de descobertas e perdas». Ciência Hoje 95:20-26. Rio de Janeiro.

, 1993c. «Endangered languages in Brazil». Trabalho apresentado no Symposium on Endangered Languages in South America, Rijks Universiteit Leiden.

\& M. P. Cavalcante, 1982. «Assimilação intrassegmental em Kaingáng». Ciência e Cultura 34(7), Suplem., 198. São Paulo.

Sandalo, M. F. S., 1991. Aspectos da língua Pirahã e a noção de polifonia. Dissertação de Mestrado, UNICAMP. 
Silva, A. C. S., 1999. Aspectos da referência alternada em Parakanã. Dissertação de mestrado, UFPA. Souza, I. de, 1988. Contribuição para a fonologia da língua Arára (Karíb). Dissertação de mestrado, UNICAMP.

Vigna, D. del, 1991.Segmentos complexos da língua Yuhúp. Dissertação de mestrado, UnB.

Weir, E. M., 1990. «Incorporation in Nadeb». Amazonian Linguistics: Studies in Lowland South American Languages (org. por D. L. Payne) 321-363. Austin: University of Texas Press.

Wetzels, L., \& W.Sluyters, 1995. «Formação de raiz, formação de glide e 'decrowding' fonético em Maxacalí». Estudos fonológicos das línguas indígenas brasileiras (org. por L. Wetzels), pp. 103-149. Rio de Janeiro: Editora UFRJ. 